\title{
Inhibitory Effects of Insulin on Intracellular Calcium and Aggregatory Response of Platelets Are Impaired in Hypertensive Subjects with Insulin Resistance
}

\author{
Ken-ichi Ishibashi*1,2, Shigeru Kageyama*2,1, Tatsuya Sakurai*1,2, Yuichi Murakawa*1, Kazuo Aihara*1, \\ Kuninobu Yokota*1,2, Ikuo Taniguchi*3, Yoshiaki Hashimoto*4, Toshiro Fujita*5, and Naoko Tajima*1
}

\begin{abstract}
To determine the effects of insulin on intracellular calcium and platelet aggregatory responses in hypertensive subjects with insulin resistance, we measured insulin sensitivity in terms of glucose disposal rate (GDR) by the hyperinsulinemic euglycemic clamp technique (GC) in 14 non-diabetic untreated hypertensive subjects, and determined basal $\left(\left[\mathrm{Ca}^{2+}\right]_{i}\right)$ and thrombin-stimulated $\left(\mathrm{T}-\left[\mathrm{Ca}^{2+}\right]_{\mathrm{i}}\right)$ platelet-free calcium concentrations and thrombin-stimulated platelet aggregatory response (AG) before $\left(\right.$ PRE $\left[\mathrm{Ca}^{2+}\right]_{i}$, T-PRE $\left[\mathrm{Ca}^{2+}\right]_{i}$, and PRE AG, respectively) and during (POST $\left[\mathrm{Ca}^{2+}\right]_{i}$, T-POST $\left[\mathrm{Ca}^{2+}\right]_{i}$, and POST AG, respectively) GC. As a control for GC, vehicle (normal saline) was infused on another day. No significant difference was observed between PRE $\left[\mathrm{Ca}^{2+}\right]_{i}$ and POST $\left[\mathrm{Ca}^{2+}\right]_{i}$, T-PRE $\left[\mathrm{Ca}^{2+}\right]_{i}$ and T-POST $\left[\mathrm{Ca}^{2+}\right]_{\mathrm{i}}$, or PRE AG and POST AG. GDR inversely correlated with $\Delta\left[\mathrm{Ca}^{2+}\right]_{\mathrm{i}}\left(\mathrm{POST}_{\left[\mathrm{Ca}^{2+}\right.}\right]_{\mathrm{i}}-$ PRE $\left.\left[\mathrm{Ca}^{2+}\right]_{\mathrm{i}}, r=-0.75, p<0.02\right), \Delta \mathrm{T}-\left[\mathrm{Ca}^{2+}\right]_{\mathrm{i}}\left(\mathrm{T}-\mathrm{POST}\left[\mathrm{Ca}^{2+}\right]_{\mathrm{i}}-\mathrm{T}-\mathrm{PRE}\left[\mathrm{Ca}^{2+}\right]_{\mathrm{i}}, r=-0.63, p<0.02\right)$ and $\triangle \mathrm{AG}$ (POST AG - PRE AG, $r=-0.67, p<0.01$ ). No significant changes were observed in these variables during vehicle infusion. $\left[\mathrm{Ca}^{2+}\right]_{i}, T-\left[\mathrm{Ca}^{2+}\right]_{i}$, and $\mathrm{AG}$ decreased during $\mathrm{GC}$ as compared with baseline in hypertensive subjects with normal insulin sensitivity, but were unchanged in those with insulin resistance, suggesting that the vasodilatory and anti-platelet aggregatory effects of insulin are impaired in patients with insulin-resistant hypertension. (Hypertens Res 1997; 20: 225-231)
\end{abstract}

Key Words: insulin resistance, calcium, platelet aggregation, glucose clamp, hypertension

The association between hypertension and insulin resistance is well recognized (1). Possible mechanisms by which insulin participates in the pathogenesis of hypertension include increased sodium reabsorption in the kidney $(2,3)$, activation of the sympathetic nervous system (4), and proliferation of vascular smooth muscle cells $(5,6)$. On the other hand, evidence against an association between hypertension and insulin resistance includes the following findings: hypertension is not observed in patients with insulinoma despite the presence of hyperinsulinemia (7), continuous infusion of highdose insulin for 7 days does not increase blood pressure in dogs $(8)$, and acute increases in plasma insulin within the physiological range increase sympathetic neural outflow but produce forearm vasodilatation and do not elevate arterial pressure in humans (9). Insulin has dual pressor and depressor (vasodilatory) effects (10). Also, insulin attenuates both agonist-stimulated vasoconstriction (11) and aggregatory response of platelets $(12,13)$.

If the vasodilatory and antiaggregatory effects of insulin were impaired in hypertensive subjects with insulin resistance, an association between hypertension and insulin resistance would be supported. We therefore measured insulin sensitivity in peripheral glucose utilization as determined by glucose clamp, intracellular calcium concentration in platelets as a marker of the vasodilatory effect of insulin on vascular smooth muscle cells, and platelet aggregation before and during glucose clamp, and examined the relationship between insulin resistance and the effects of insulin on intracellular calcium concentration and platelet aggregation in hypertensive subjects.

\section{Methods}

The subjects were 14 men with non-diabetic untreated essential hypertension. Insulin sensitivity in terms of glucose disposal rate (GDR) was determined by an artificial endocrine pancreas using the hyperinsulinemic euglycemic clamp technique (GC). Venous blood was drawn from subjects to measure

From the *1Department of Internal Medicine (III), ${ }^{* 2}$ Division of Clinical Pharmacology and Therapeutics, and * ${ }^{3}$ Department of Internal Medicine (IV), Jikei University School of Medicine, Tokyo, Japan, and * ${ }^{4}$ Department of Clinical Laboratory Medicine, and *5Department of Internal Medicine (IV), Faculty of Medicine, University of Tokyo, Tokyo, Japan.

Address for Reprints: Shigeru Kageyama, M.D., Devision of Clinical Pharmacology and Therapeutics, Jikei University School of Medicine, 3-25-8 Nishi-Shinbashi, Minato-ku, Tokyo 105, Japan.

Received May 15, 1997; accepted in revised form July 28, 1997. 
basal $\left(\left[\mathrm{Ca}^{2+}\right]_{\mathrm{i}}\right)$ and thrombin-stimulated $\left(\mathrm{T}-\left[\mathrm{Ca}^{2+}\right]_{\mathrm{i}}\right)$ platelet free calcium concentrations as well as thrombin-stimulated platelet aggregatory responses (AG) before (PRE $\left[\mathrm{Ca}^{2+}\right]_{i}, \quad$ T-PRE $\left[\mathrm{Ca}^{2+}\right]_{i}$, and PRE AG, respectively) and after $115 \mathrm{~min}$ of GC $\left(\right.$ POST $\left[\mathrm{Ca}^{2+}\right]_{i}$, T-POST $\left[\mathrm{Ca}^{2+}\right]_{i}$, and POST AG, respectively). Before venous blood sampling, systolic blood pressure (SBP), diastolic blood pressure (DBP), and heart rate (HR) were measured with a sphygmomanometer with the patient in the supine position both before (PRE-SBP, PRE-DBP, and PRE-HR, respectively) and during (POST-SBP, POST-DBP, and POST-HR, respectively) GC. Serum immunoreactive insulin level (IRI) was measured at $115 \mathrm{~min}$ of GC. As a control for GC, an infusion of vehicle (normal saline) was given to all subjects on another day. The subjects were free from other diseases as determined by case history, physical examination, and routine laboratory screening. This study was approved by the Medical Research Review Board of Jikei University, and informed written consent for participation was obtained from each subject.

\section{Glucose Clamp Studies}

GC was performed to assess insulin sensitivity with an artificial endocrine pancreas (Biostator, Life Science Instruments, Indiana) after an overnight fast $(14,15)$. On the study day, the subjects arrived at the artificial endocrine pancreas room by 8:30 AM. A cannula was inserted into a left antecubital vein to aspirate blood $(2 \mathrm{ml} / \mathrm{h})$ for continuous blood glucose monitoring by the artificial endocrine pancreas. A cannula was inserted into a superficial vein at the ankle joint to infuse insulin and glucose. To maintain catheter patency, saline was infused continuously at a rate of $0.5 \mathrm{ml} / \mathrm{min}$ from $9 \mathrm{AM}$ to noon. From $9 \mathrm{AM}$ to $10 \mathrm{AM}$, blood glucose was continuously monitored, and insulin was not infused. From $10 \mathrm{AM}$ to noon, GC was performed.

Insulin (Novolin R, Novo-Nordisk, Denmark) infusate was prepared in normal saline, to which $4 \mathrm{ml}$ of the subject's blood per $100 \mathrm{ml}$ infusate was added to prevent adsorption of insulin onto plastic surfaces $(14,16)$. Insulin $(300 \mathrm{mU} / \mathrm{ml})$ was administered as a priming dose followed by continuous infusion. In the first 10 -min priming period, the total amount of insulin administered was twice that administered during the subsequent $110 \mathrm{~min}$, when insulin was infused at a rate of $40 \mathrm{mU} / \mathrm{m}^{2}$ body surface area per min. In the first $5 \mathrm{~min}$ of the priming period, two-thirds of the priming dose was infused, and in the next $5 \mathrm{~min}$ of the priming period the remaining one-third of the priming dose was infused to mimic a logarithmically falling manner of priming (16). Blood glucose was maintained at the fasting level by infusing $20 \%$ glucose according to mode 9:1 of the Biostator (17). GC was continued for 120 min. GDR during the last $30 \mathrm{~min}$ of GC was used as an index of insulin sensitivity. The subjects remained lying quietly on a bed throughout the entire course of the study.
Table 1. Clinical Characteristics of Subjects

\begin{tabular}{lc}
\hline \multicolumn{1}{c}{ Characteristic } & Means $\pm \mathrm{SD}$ \\
\hline Age $(\mathrm{yr})$ & $44 \pm 6$ \\
Body mass index $\left(\mathrm{kg} / \mathrm{m}^{2}\right)$ & $24.0 \pm 2.6$ \\
Systolic blood pressure $(\mathrm{mmHg})$ & $146 \pm 10$ \\
Diastolic blood pressure $(\mathrm{mmHg})$ & $95 \pm 7$ \\
Pulse rate $(/ \mathrm{min})$ & $68 \pm 10$ \\
Total cholesterol $(\mathrm{mg} / \mathrm{dl})$ & $200 \pm 33$ \\
HDL cholesterol $(\mathrm{mg} / \mathrm{dl})$ & $53 \pm 13$ \\
Triglyceride $(\mathrm{mg} / \mathrm{dl})$ & $89 \pm 44$ \\
Fasting plasma glucose $(\mathrm{mg} / \mathrm{dl})$ & $99 \pm 8$ \\
F-IRI $(\mu \mathrm{U} / \mathrm{ml})$ & $6.7 \pm 3.8$ \\
\hline
\end{tabular}

F-IRI, fasting serum immunoreactive insulin.

\section{Measurement of Intracellular Calcium Concentration and Platelet Aggregation}

Blood was mixed with $1 / 10$ volume of $3.8 \%$ trisodium citrate and centrifuged at $1,200 \mathrm{rpm}$ for 10 min at room temperature. The upper phase plateletrich plasma (PRP) was incubated with $1 \mathrm{mM}$ fura 2AM in dimethyl sulfoxide, adjusted to a final concentration of $1 \mu \mathrm{M}$, for $45 \mathrm{~min}$ at $37^{\circ} \mathrm{C}$.

Fura 2-loaded PRP was mixed with $1 / 5$ volume of acid-citrate-dextrose solution $(\mathrm{ACD}, 0.80 \mathrm{w} / \mathrm{v} \% \mathrm{ci}$ trate, $2.20 \mathrm{w} / \mathrm{v} \%$ sodium citrate, and $2.20 \mathrm{w} / \mathrm{v} \%$ dextrose) and centrifuged at 2,500 rpm for $10 \mathrm{~min}$ at room temperature. The pellet obtained was suspended in washing buffer ( $134 \mathrm{mM} \mathrm{NaCl}, 5 \mathrm{mM}$ dextrose, $1 \mathrm{mM}$ EDTA, $15 \mathrm{mM}$ Tris, $\mathrm{pH} \mathrm{6.3)}$ and recentrifuged at $2,500 \mathrm{rpm}$ for $10 \mathrm{~min}$ at room temperature. The resulting pellet was resuspended in Hepes-Tyrode buffer $(129 \mathrm{mM} \mathrm{NaCl}, 2.8 \mathrm{mM}$ $\mathrm{KCl}, 0.8 \mathrm{mM} \mathrm{KH} \mathrm{KO}_{4}, 8.9 \mathrm{mM} \mathrm{NaHCO} 3,0.8 \mathrm{mM}$ $\mathrm{MgCl}_{2}$, $5.6 \mathrm{mM}$ dextrose, $10 \mathrm{mM}$ Hepes, $\mathrm{pH} 7.4$ ), adjusted to a final concentration of $3 \times 10^{8}$ platelets/ $\mathrm{ml}$.

$\left[\mathrm{Ca}^{2+}\right]_{\mathrm{i}}$ was measured in a fura 2-AM-loaded platelet suspension that had been incubated with $\mathrm{CaCl}_{2}$ (final concentration: $1 \mathrm{mM}$ ). The platelets were stirred at $37^{\circ} \mathrm{C}$ in a CAF-100 $\mathrm{Ca}^{2+}$ analyzer (Jasco, Japan Spectroscopic Co., Ltd., Tokyo). The instrument was set at excitation wavelengths of 340 and $380 \mathrm{~nm}$ and an emission wavelength of $500 \mathrm{~nm}$. We measured both resting and thrombin (final concentration: $0.5 \mathrm{U} / \mathrm{ml}$ )-stimulated fluorescence of the sample at $340 \mathrm{nM}\left(\mathrm{F}_{1}\right)$ and fluorescence at $380 \mathrm{~nm}$ $\left(F_{2}\right)$. Maximum fluorescence $\left(F_{1 \max }, F_{2 \max }\right)$ was achieved by adding Triton X-100 (final concentration: $0.2 \%)$. This corresponded to complete complexation of fura 2 with $\mathrm{Ca}^{2+}$. Minimum fluorescence $\left(F_{1 \min }, F_{2 \min }\right)$ was obtained in the presence of EGTA (final concentration, $10 \mathrm{mM}$ ). $\left[\mathrm{Ca}^{2+}\right]_{\mathrm{i}}$ was calculated according to the formula of Grynkiewicz et al. (18):

$\left[\mathrm{Ca}^{2+}\right]_{\mathrm{i}}=\mathrm{Kd}\left(\mathrm{R}-\mathrm{R}_{\min }\right) /\left(\mathrm{R}_{\max }-\mathrm{R}\right) \mathrm{b}(\mathrm{nM})$, where $\mathrm{Kd}$ is the binding constant, $\mathrm{R}$ is the ratio of fluorescences of the sample at 340 and $380 \mathrm{~nm}\left(\mathrm{~F}_{1} /\right.$ $\left.F_{2}\right), R_{\max }$ and $R_{\min }$ are the ratios of fura 2 free acid at 340 and $380 \mathrm{~nm}$ in the presence of saturating calcium (with Triton X-100) and EGTA, respectively, 
Table 2. Comparison between Insulin Resistant Group and Normal Insulin Sensitivity Group with Respect to Blood Pressure and Heart-Rate-Related Variables during Glucose Clamp

\begin{tabular}{lcc}
\hline & Insulin resistant $(n=8)$ & Insulin sensitive $(n=6)$ \\
\hline PRE-SBP (mmHg) & $148 \pm 11$ & $143 \pm 8$ \\
POST-SBP (mmHg) & $147 \pm 8$ & $149 \pm 12$ \\
$\Delta$ SBP (mmHg) & $-6 \pm 12$ & $5 \pm 12$ \\
PRE-DBP (mmHg) & $94 \pm 11$ & $98 \pm 5$ \\
POST-DBP (mmHg) & $97 \pm 12$ & $94 \pm 5$ \\
DDBP (mmHg) & $3 \pm 7$ & $-4 \pm 5$ \\
PRE-HR (/min) & $72 \pm 13$ & $63 \pm 9$ \\
POST-HR (/min) & $77 \pm 15$ & $67 \pm 8$ \\
SHR (/min) & $5 \pm 8$ & $4 \pm 5$ \\
\hline
\end{tabular}

Values are expressed as means $\pm \mathrm{SD}$. Insulin resistant, GDR $<7 \mathrm{mg} / \mathrm{kg}$ per $\mathrm{min}$; Insulin sensitive, GDR $>7 \mathrm{mg} / \mathrm{kg}$ per $\min$.

and $b$ is the ratio of fluorescence at $380 \mathrm{~nm}$ in the presence of EGTA to that at $380 \mathrm{~nm}$ in the presence of Triton $\mathrm{X}-100\left(\mathrm{~F}_{2 \min } / \mathrm{F}_{2 \max }\right)$. The dissociation constant of fura 2 for calcium was taken to be 224 $\mathrm{nmol} / 1$ at $37^{\circ} \mathrm{C}$.

For aggregation studies, the change in optical density in plasma was measured using the same instrument as for $\left[\mathrm{Ca}^{2+}\right]_{i}$, but with the setting adjusted for aggregation measurements. Calibration was performed with PRP as zero aggregation, and plateletpoor plasma (obtained by centrifugation of an aliquot of the same blood sample for another $10 \mathrm{~min}$ at 2,500 rpm) as maximal aggregation. The instrument was recalibrated after each experiment. Aggregation was measured in continuously stirred $(1,000 \mathrm{rpm})$ thrombin-stimulated platelets at $37^{\circ} \mathrm{C}$, and expressed as a percentage of maximal aggregation.

\section{Vehicle Infusion}

As a control for GC, an infusion of vehicle (normal saline) was given to all subjects on another day. The protocol used was the same, except that GC was not performed. Saline solution equal in volume to the vehicle for insulin was infused for $2 \mathrm{~h}$ by a syringe pump (Atom, Tokyo, Japan), and venous blood was drawn from all subjects before and after $115 \mathrm{~min}$ of vehicle infusion.

\section{Statistics}

Values are expressed as means \pm SD. Statistical comparisons were performed with the paired twotailed Student's $t$-test. Correlations were assessed by standard linear regression. $P$ values less than 0.05 were considered to indicate statistical significance.

\section{Results}

The clinical characteristics of the subjects are shown in Table 1. The steady-state serum immunoreactive insulin level after $115 \mathrm{~min}$ of $\mathrm{GC}$ was $82.0 \pm 11.6$ $\mu \mathrm{U} / \mathrm{ml}$.
Insulin Sensitivity and the Effects of Insulin on SBP, $D B P$, and $H R$

Although no significant difference was observed between PRE-SBP and POST-SBP (146 $\pm 10 v s .148$ $\pm 10 \mathrm{mmHg}$, n.s.) or between PRE-DBP and POST-DBP ( $96 \pm 9$ vs. $95 \pm 10 \mathrm{mmHg})$, POST-HR was significantly higher than PRE-HR $(68 \pm 12 v s$. $72 \pm 13, p<0.04)$. There was no correlation between GDR and PRE-SBP $(r=-0.33$, n.s. $)$, PREDBP $(r=0.30$, n.s. $)$, PRE-HR $(r=-0.27$, n.s. $)$, POST-SBP $(r=0.01$, n.s.), POST-DBP $(r=-0.06$, n.s.) or POST-HR $(r=-0.25$, n.s. $)$, or between GDR and $\triangle$ SBP (POST-SBP - PRE-SBP, $r=0.28$, n.s.), $\triangle$ DBP (POST-DBP - PRE-DBP, $\mathrm{r}=-0.47$, n.s.), or $\Delta \mathrm{HR}$ (POST-HR - PRE-HR, $\mathrm{r}=-0.01$, n.s.). In order to investigate significant differences in these valiables between insulin resistant subjects and insulin sensitive subjects, we divided them into two groups: those with GDR being $<7 \mathrm{mg} / \mathrm{kg}$ per min, and those with GDR being $>7 \mathrm{mg} / \mathrm{kg}$ per min. However, there was no statistically significant difference in these variables between the two groups (Table 2).

Insulin Sensitivity and the Effect of Insulin on $\left[\mathrm{Ca}^{2+}\right]_{i}$

Although no significant difference was observed between PRE $\left[\mathrm{Ca}^{2+}\right]_{\mathrm{i}}$ and POST $\left[\mathrm{Ca}^{2+}\right]_{\mathrm{i}}(61.2 \pm 9.8 v s$. $59.8 \pm 10.9 \mathrm{nM})$ and no significant correlation was observed between GDR and PRE $\left[\mathrm{Ca}^{2+}\right]_{\mathrm{i}}(r=0.37$, n.s.) (Fig. 1-a), GDR was inversely correlated with both POST $\left[\mathrm{Ca}^{2+}\right]_{\mathrm{i}}(r=-0.62, p<0.02)$ (Fig. 1-b) and the change in $\left[\mathrm{Ca}^{2+}\right]_{i}$ from before to during GC $\left(\Delta\left[\mathrm{Ca}^{2+}\right]_{\mathrm{i}}:\right.$ POST $\left.\left[\mathrm{Ca}^{2+}\right]_{\mathrm{i}}-\mathrm{PRE}\left[\mathrm{Ca}^{2+}\right]_{\mathrm{i}}\right) \quad(r=$ $-0.75, p<0.02$ ) (Fig. 1-c). In the comparison of the two groups, the change in $\left[\mathrm{Ca}^{+}\right]_{i}$ was significantly less in the insulin resistant group than in the insulin sensitive group (Table 3).

Insulin Sensitivity and the Effect of Insulin on Thrombin-Stimulated $\left[\mathrm{Ca}^{2+}\right]_{i}$

Although GDR positively correlated with TPRE $\left[\mathrm{Ca}^{2+}\right]_{\mathrm{i}}(r=0.71, p<0.01)$ (Fig. 2-a), no significant correlation was observed between GDR and T-POST $\left[\mathrm{Ca}^{2+}\right]_{\mathrm{i}}(r=0.01$, n.s. $)$ (Fig. 2-b). 

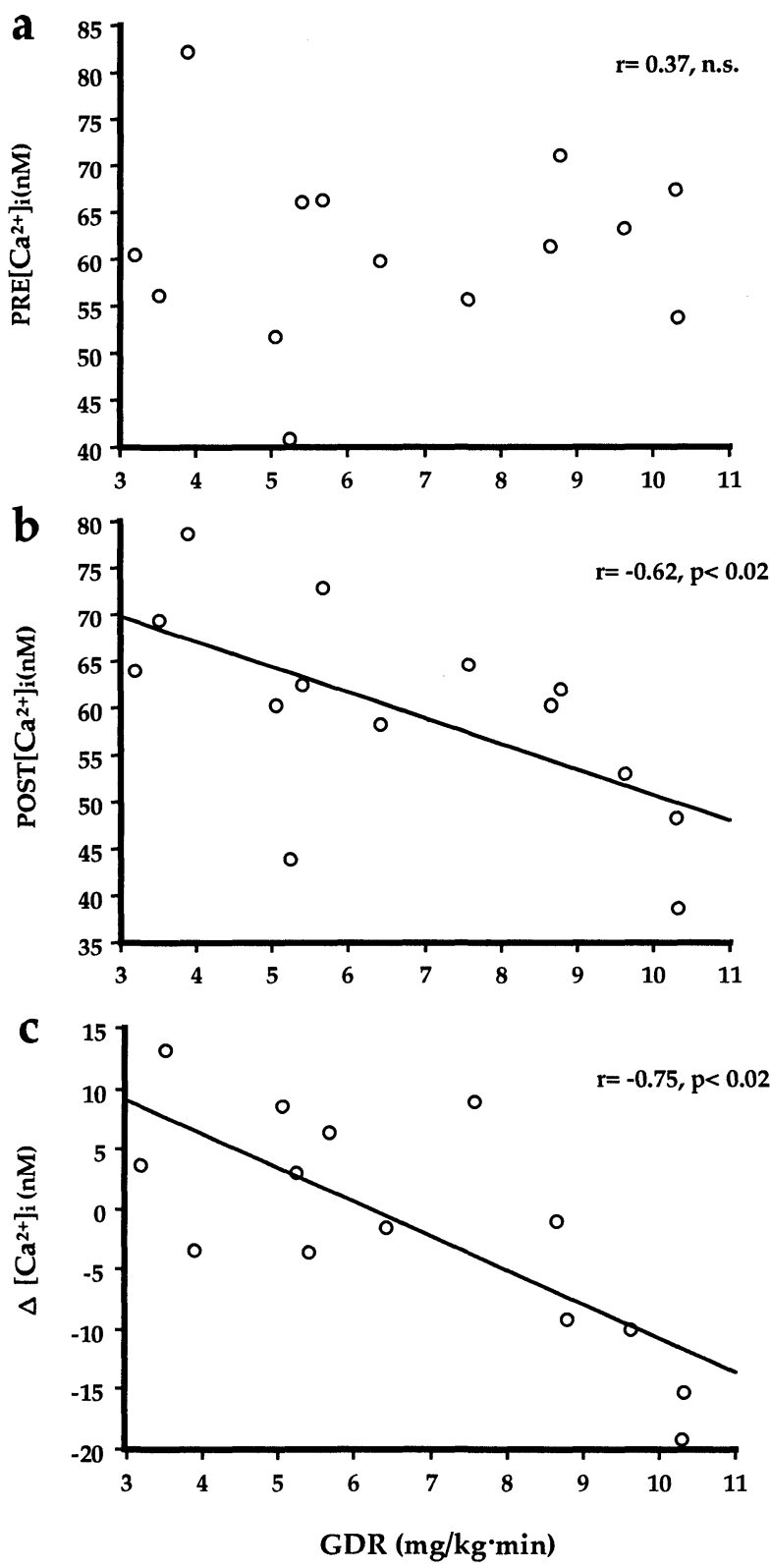

Fig. 1. Effects of insulin on basal platelet cytosolic free calcium concentration ([Ca $\left.\mathrm{Ca}^{2+}\right]_{i}$ in hypertensive subjects. a) Relationship between glucose disposal rate (GDR) and $\left[\mathrm{Ca}^{2+}\right]_{i}$ before glucose clamp (GC) (PRE $\left[\mathrm{Ca}^{2+}\right]_{i}(\mathrm{r}=$ 0.37 , n.s.). b) Relationship between $G D R$ and $\left[\mathrm{Ca}^{2+}\right]_{i}$ during GC (POST $\left[\mathrm{Ca}^{2+}\right]_{i}(\mathrm{r}=-0.62, \mathrm{p}<0.02)$. c) Relationship between glucose disposal rate $(G D R)$ and $\Delta$ $\left[\mathrm{Ca}^{2+}\right]_{i}\left(\mathrm{POST}\left[\mathrm{Ca}^{2+}\right]_{i}-\mathrm{PRE}\left[\mathrm{Ca}^{2+}\right]_{i}\right)$ by $G C(\mathrm{r}=-0.75$, $\mathrm{p}<0.02)$.

Although no significant difference was observed between T-PRE $\left[\mathrm{Ca}^{2+}\right]_{\mathrm{i}}$ and T-POST $\left[\mathrm{Ca}^{2+}\right]_{\mathrm{i}}(670 \pm$ 151 vs. $646 \pm 200 \mathrm{nM})$, GDR inversely correlated with the change in $\mathrm{T}-\left[\mathrm{Ca}^{2+}\right]_{\mathrm{i}}$ from before to during GC $\left(\Delta \mathrm{T}-\left[\mathrm{Ca}^{2+}\right]_{\mathrm{i}}: \mathrm{T}-\mathrm{POST}\left[\mathrm{Ca}^{2+}\right]_{\mathrm{i}}-\mathrm{T}-\mathrm{PRE}\left[\left[\mathrm{Ca}^{2+}\right]_{\mathrm{i}}\right)\right.$ $(r=-0.63, p<0.02$ ) (Fig. $2-c)$. In the comparison of the two groups, T-PRE $\left[\mathrm{Ca}^{2+}\right]_{i}$ was significantly less in the insulin resistant group than in the insulin
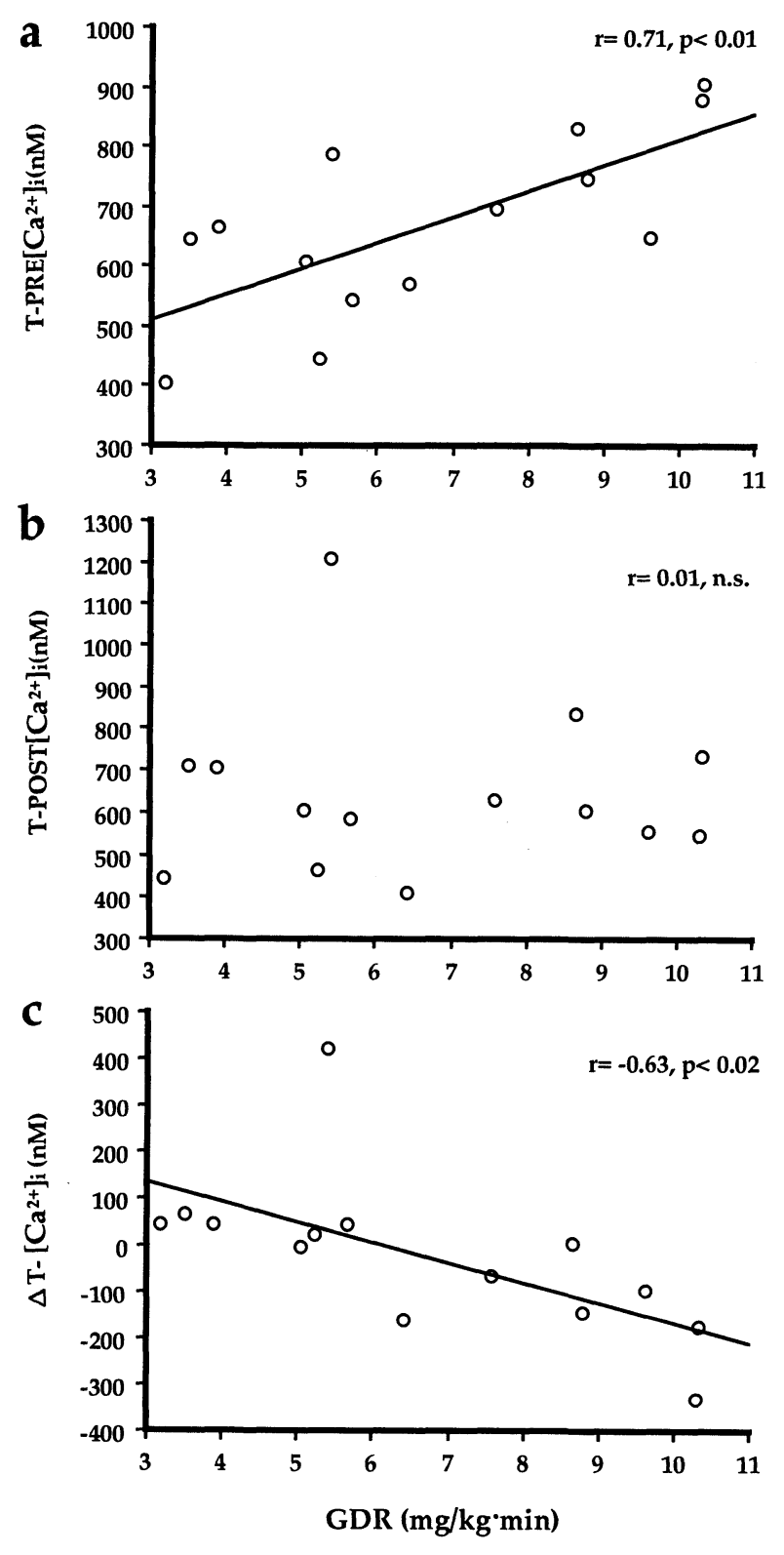

Fig. 2. Effects insulin on thrombin-stimulated platelet cytosolic free calcium concentration $\left(T-\left[\mathrm{Ca}^{2+}\right]_{i}\right.$ in hypertensive subjects. a) Relationship between glucose disposal rate (GDR) and $\mathrm{T}-\left[\mathrm{Ca}^{2+}\right]_{i}$ before glucose clamp (GC) (T-PRE $\left[\mathrm{Ca}^{2+}\right]_{i}(\mathrm{r}=0.71, \mathrm{p}<0.01)$. b) Relationship between GDR and T-[Ca $\left.\mathrm{Ca}^{2+}\right]_{i}$ during GC(T-POST $\left.\left[\mathrm{Ca}^{2+}\right]_{i}\right)(\mathrm{r}=-0.01$, n.s.). c) Relationship between GDR and $\triangle T-\left[\mathrm{Ca}^{2+}\right]_{i}\left(T-P O S T\left[\mathrm{Ca}^{2+}\right]_{i}-T-P R E\left[\mathrm{Ca}^{2+}\right]_{i}\right)$ by $G C(\mathrm{r}=-0.63, \mathrm{p}<0.02)$.

sensitive group and the change in $\mathrm{T}-\left[\mathrm{Ca}^{2+}\right]_{i}$ was significantly less in the insulin resistant group than in the insulin sensitive group (Table 3 ).

Insulin Sensitivity and the Effect of Insulin on Platelet Aggregation

Although no significant difference was observed between PRE-AG and POST-AG (81 \pm 8 vs. $76 \pm$ 


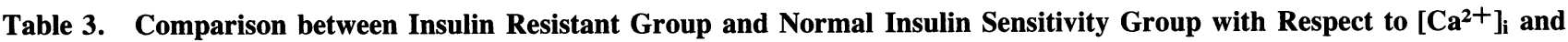
Aggregation-Related Variables during Glucose Clamp

\begin{tabular}{lcc}
\hline & Insulin resistant $(n=8)$ & Insulin sensitive $(n=6)$ \\
\hline PRE $\left[\mathrm{Ca}^{2+}\right]_{\mathrm{i}}$ & $60.4 \pm 12.1$ & $62.1 \pm 6.6$ \\
POST $\left[\mathrm{Ca}^{2+}\right]_{\mathrm{i}}$ & $63.7 \pm 10.5$ & $54.5 \pm 9.9$ \\
$\Delta\left[\mathrm{Ca}^{2+}\right]_{\mathrm{i}}$ & $3.3 \pm 6.0^{*}$ & $-7.6 \pm 10.1$ \\
$\mathrm{~T}-\mathrm{PRE}\left[\mathrm{Ca}^{2+}\right]_{\mathrm{i}}$ & $583 \pm 123^{* *}$ & $785 \pm 103$ \\
$\mathrm{~T}-\mathrm{POST}\left[\mathrm{Ca}^{2+}\right]_{\mathrm{i}}$ & $642 \pm 256$ & $651 \pm 113$ \\
$\Delta \mathrm{T}-\left[\mathrm{Ca}^{2+}\right]_{\mathrm{i}}$ & $59 \pm 163^{*}$ & $-134 \pm 115$ \\
PRE-AG & $78 \pm 8$ & $84 \pm 5$ \\
POST-AG & $79 \pm 10$ & $73 \pm 4$ \\
$\Delta \mathrm{AG}$ & $1 \pm 8^{* *}$ & $-13 \pm 6$ \\
\hline
\end{tabular}

Values are expressed as means $\pm \mathrm{SD}$. Insulin resistant, GDR $<7 \mathrm{mg} / \mathrm{kg}$ per $\mathrm{min}$; Insulin sensitive, GDR $>7 \mathrm{mg} / \mathrm{kg} \mathrm{per}$ $\min .{ }^{*} p<0.05,{ }^{* *} p<0.01$.

$8 \%)$ and GDR did not correlate with either PREAG or POST-AG $(r=0.32$, n.s. $v s . r=-0.42$, n.s. $)$ (Fig. 3-a, 3-b), GDR inversely correlated with the change in $A G$ from before to during $\mathrm{GC}(\triangle \mathrm{AG}$ : POST-AG - PRE-AG) $(r=-0.67, \quad p<0.01)$ (Fig. 3-c).

A positive correlation was observed between the change in thrombin-stimulated $\left[\mathrm{Ca}^{2+}\right]_{\mathrm{i}}$ and the change in aggregation from before to during GC $(r$ $=0.55, p<0.05)$ (Fig. 4). In the comparison of the two groups, the change in AG was significantly less in the insulin resistant group than in the insulin sensitive group (Table 3 ).

\section{Vehicle Infusion}

No significant difference was observed between PRE-SBP and POST-SBP (146 \pm 10 vs. $146 \pm 10$ $\mathrm{mmHg}$, n.s.), PRE-DBP and POST-DBP (94 \pm 9 vs. $96 \pm 10 \mathrm{mmHg}$ ), or PRE-HR and POST-HR (68 \pm 12 vs. $70 \pm 13$, n.s.). There was no correlation between GDR and PRE-SBP $(r=-0.23$, n.s. $)$, PRE-DBP $(r=0.28, \quad$ n.s. $), \quad$ PRE-HR $(r=-0.32$, n.s.), POST-SBP $(r=0.14$, n.s. $)$, POST-DBP $(r=$ -0.03 , n.s.) or POST-HR $(r=-0.38$, n.s. $)$, or between GDR and $\triangle$ SBP $(r=0.21$, n.s. $), \triangle \mathrm{DBP}(r=$ -0.34 , n.s. $)$, or $\Delta \mathrm{HR}(r=-0.22$, n.s. $)$ during vehicle infusion.

No significant difference was observed between $\operatorname{PRE}\left[\mathrm{Ca}^{2+}\right]_{\mathrm{i}}$ and POST $\left[\mathrm{Ca}^{2+}\right]_{\mathrm{i}}(64.9 \pm 11.6$ vs. 64.0 $\pm 11.1 \mathrm{nM})$, T-PRE $\left[\mathrm{Ca}^{2+}\right]_{\mathrm{i}}$ and T-POST $\left[\mathrm{Ca}^{2+}\right]_{\mathrm{i}}$ $(703 \pm 139$ vs. $721 \pm 146 \mathrm{nM})$, or between PRE AG and POST AG $(81 \pm 9$ vs. $80 \pm 7 \%)$. There was no correlation between GDR and PRE $\left[\mathrm{Ca}^{2+}\right]_{\mathrm{i}}(r=$ -0.54 , n.s. $)$, T-PRE $\left[\mathrm{Ca}^{2+}\right]_{\mathrm{i}}(r=0.50$, n.s. $)$, PRE $\operatorname{AG}(r=-0.20, \quad$ n.s. $), \quad$ POST $\left[\mathrm{Ca}^{2+}\right]_{\mathrm{i}}(r=-0.15$, n.s.), T-POST $\left[\mathrm{Ca}^{2+}\right]_{\mathrm{i}}(r=0.37$, n.s. $)$, or POST AG $(r=-0.35$, n.s. $)$, or between GDR and $\Delta\left[\mathrm{Ca}^{2+}\right]_{\mathrm{i}}(r$ $=-0.37$, n.s. $), \Delta \mathrm{T}-\left[\mathrm{Ca}^{2+}\right]_{\mathrm{i}}(r=0.09$, n.s. $)$, or $\Delta \mathrm{AG}$ $(r=-0.21$, n.s. $)$ during vehicle infusion.

\section{Discussion}

The difference between baseline and insulin-stimulated $\left[\mathrm{Ca}^{2+}\right]_{\mathrm{i}}$ values was found to be inversely correlated with insulin sensitivity in terms of GDR.
Thus, $\left[\mathrm{Ca}^{2+}\right]_{i}$ decreased after insulin infusion in hypertensive subjects with normal insulin sensitivity, but was unchanged or increased slightly in those with insulin resistance. Results of studies of the effects of insulin on $\left[\mathrm{Ca}^{2+}\right]_{i}$ metabolism have been inconsistent. In animals, insulin has been reported to increase $\left[\mathrm{Ca}^{2+}\right]_{\mathrm{i}}(19,20)$, decrease $\left[\mathrm{Ca}^{2+}\right]_{\mathrm{i}}(21)$ or have no effect on it $(22,23)$. In a human study, insulin has been reported not to change platelet $\left[\mathrm{Ca}^{2+}\right]_{\mathrm{i}}$ of normotensive subjects in vitro and in vivo (24). The above discrepancies may reflect differences in experimental conditions, such as kind of cells, insulin concentration and duration of co-incubation time. However, a possible reason for this variability in results is lack of determination of insulin sensitivity in these studies. Consistent with the findings of these previous studies, platelet $\left[\mathrm{Ca}^{2+}\right]_{i}$ did not change from before to during glucose clamp in the present study either, unless insulin sensitivity is considered. Baseline $\left[\mathrm{Ca}^{2+}\right]_{\mathrm{i}}$ did not correlate with insulin sensitivity in the present study. Low insulin concentrations of fasting level do not seem to affect $\left[\mathrm{Ca}^{2+}\right]_{\mathrm{i}}$.

Since the reduction in $\left[\mathrm{Ca}^{2+}\right]_{\mathrm{i}}$ is thought to be caused by stimulation of $\mathrm{Ca}^{2+}$-ATPase $(25)$ or $\mathrm{Na}^{+}$, $\mathrm{K}^{+}$-ATPase $(11,26)$, or both, by insulin, our findings show that insulin resistance occurs not only in its main action of glucose uptake, but also in other actions. In an animal model of insulin-resistant hypertension, Zucker obese rats, $\mathrm{Ca}^{2+}$-ATPase activity is lower than in lean controls, although there is no difference in $\mathrm{Na}^{+}, \mathrm{K}^{+}$-ATPase activity between the two (27). These findings suggest that resistance in $\mathrm{Ca}^{2+}$-ATPase activity following stimulation by insulin might explain the lack of reduction in platelet $\left[\mathrm{Ca}^{2+}\right]_{\mathrm{i}}$ in hypertensive subjects with insulin resistance.

We also demonstrated that the changes in thrombin-stimulated $\left[\mathrm{Ca}^{2+}\right]_{i}$ and aggregatory responses from before to during GC inversely correlated with insulin sensitivity. These findings indicate that thrombin-evoked $\left[\mathrm{Ca}^{2+}\right]_{\mathrm{i}}$ and aggregatory responses are inhibited by insulin in hypertensive subjects with normal insulin sensitivity, and that these inhibitory effects are blunted in hypertensive sub- 

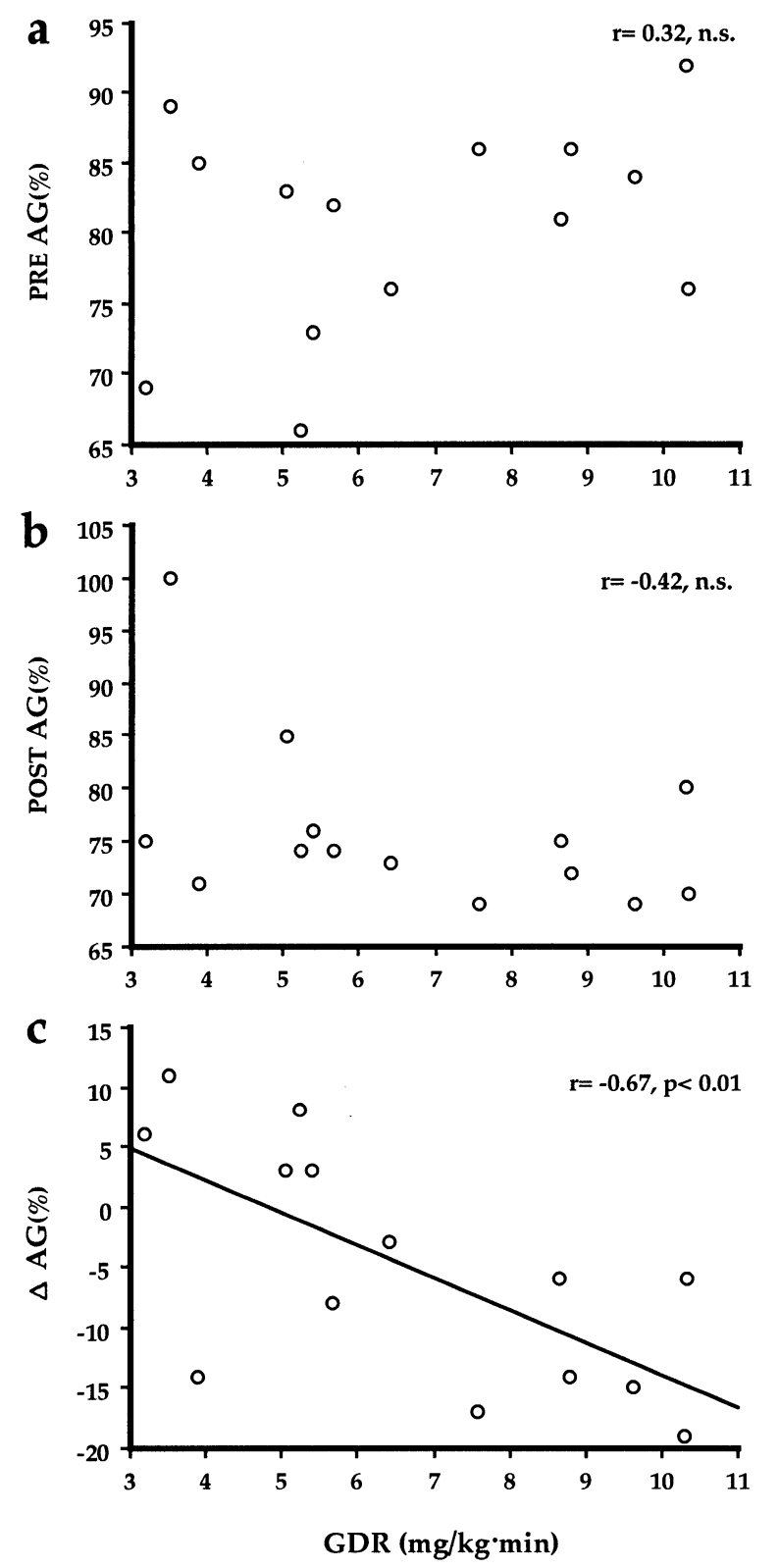

Fig. 3. Effects of insulin on thrombin-stimulated aggregation $(A G)$ in hypertensive subjects. a) Relationship between glucose disposal rate (GDR) and AG before glucose clamp (GC) (PRE AG) (r=0.32, n.s.) b) Relationship between $G D R$ and $A G$ during GC (POST $A G)(\mathrm{r}=-0.42$, n.s.). c) Relationship between GDR and $\triangle A G$ (POST $A G$ $-P R E A G)$ by $G C(\mathrm{r}=-0.67, \mathrm{p}<0.01)$.

jects with insulin resistance. A mechanism by which insulin might attenuate platelet aggregation is inhibition of thrombin-evoked $\left[\mathrm{Ca}^{2+}\right]_{i}$, since a positive correlation was observed between the change in thrombin-stimulated $\left[\mathrm{Ca}^{2+}\right]_{i}$ and the change in aggregation from before to during glucose clamp.

Insulin signal transduction has branches on its pathway. Therefore, it may be possible that certain actions of insulin are impaired and others are not.

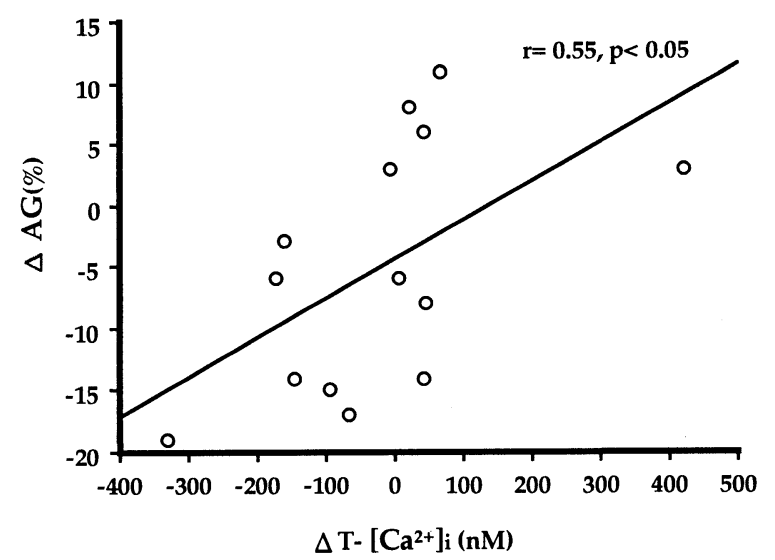

Fig. 4. Relationship between the change in thrombinstimulated $\left[\mathrm{Ca}^{2+}\right]_{i}\left(\Delta \mathrm{T}-\left[\mathrm{Ca}^{2+}\right]_{i}\right)$ and the change in aggregation $(\triangle A G)$ from before to during $G C(\mathrm{r}=0.55, \mathrm{p}$ $<0.05)$.

Among insulin's pressor mechanisms, insulin resistance has been reported not to exist with respect to stimulation of sodium reabsorption in the kidney (28) and sympathetic activation (29). Insulin has been reported to attenuate vasoactive agonist-stimulated vasoconstriction in vascular smooth muscle by inhibiting agonist-evoked increase in $\left[\mathrm{Ca}^{2+}\right]_{\mathrm{i}}(11$, 21). These effects of insulin have been shown to be impaired in animals with insulin resistance (21). The present study revealed that insulin attenuates platelet aggregation by the same mechanism as in vascular smooth muscle, and that these effects of insulin are also impaired in patients with insulin resistance. However, whether or not resistance develops to the depressor effects of insulin in humans has yet to be clearly determined. If the same phenomenon as observed in platelet $\mathrm{Ca}^{2+}$ metabolism also occurred in vascular smooth muscle cells, this would show that insulin induces vasodilation by decreasing $\left[\mathrm{Ca}^{2+}\right]_{i}$ in hypertensive subjects with normal insulin sensitivity, but that the vasodilatory effect of insulin is attenuated in those with insulin resistance.

A negative correlation has been reported between blood pressure and thrombin-evoked $\left[\mathrm{Ca}^{2+}\right]_{i}$ because subjects with higher blood pressures have impaired $\mathrm{Ca}^{2+}$ influx by thrombin stimulation (30). The positive correlation that we observed between insulin sensitivity and baseline thrombin-evoked $\left[\mathrm{Ca}^{2+}\right]_{\mathrm{i}}$ may therefore imply that hypertensive subjects with insulin resistance have impaired $\mathrm{Ca}^{2+}$ influx by thrombin stimulation.

Heart rate during $\mathrm{GC}$ was significantly higher than the baseline value in our subjects. No significant correlation was observed between the change in heart rate and insulin sensitivity. Blood pressure did not change during GC, either. We measured blood pressure only before and at the end of GC to avoid activation of platelet aggregation by cuff inflation. Further investigations of the relationships between heart rate and blood pressure change and insulin sensitivity are needed. 
In conclusion, insulin-induced reduction in $\left[\mathrm{Ca}^{2+}\right]_{i}$ in platelets was impaired in hypertensive patients with insulin resistance. Thrombin-evoked increases in $\left[\mathrm{Ca}^{2+}\right]_{i}$ and platelet aggregation were inhibited by insulin in hypertensive subjects with normal insulin sensitivity, whereas these effects were blunted in hypertensive subjects with insulin resistance. These findings suggest that insulin resistance exists not only in glucose uptake but also in $\mathrm{Ca}^{2+}$ metabolism in hypertensive subjects. This fact implies that insulin acts as a pressor hormone in subjects with insulin resistance and may thereby contribute to the development of hypertension.

\section{Acknowledgements}

The authors are grateful to Mrs. N. Shibano and Mrs. M. Kammuri for their excellent technical assistance in the determination of intracellular calcium concentration and in aggregation of platelets.

\section{References}

1. Ferrannini E, Buzzigoli G, Bonadonna R, et al: Insulin resistance in essential hypertension. $N$ Engl $J$ Med 1987; 317: 350-357.

2. DeFronzo RA, Cooke CR, Andres R, Faloona GR, Davis PJ: The effect of insulin on renal handling of sodium, potassium, calcium, and phosphate in man. $J$ Clin Invest 1975 ; 55: 845-855.

3. Kageyama S, Yamamoto J, Isogai Y, Fujita T: Effect of insulin on sodium reabsorption in hypertensive patients. Am J Hypertens 1994; 7: 409-415.

4. Rowe JW, Young JB, Minaker KL, Stevens AL, Pallotta J, Landsberg L: Effect of insulin and glucose infusions on sympathetic nervous system activity in normal man. Diabetes 1981; 30: 219-225.

5. Pfeifle B, Ditschuneit $\mathrm{HH}$, Ditschuneit $\mathrm{H}$ : Insulin as a cellular growth regulator of rat arterial smooth muscle cells in vitro. Horm Metab Res 1980; 12: 381385 .

6. Stout RW: Insulin and atheroma. 20-yr perspective [see comments]. Diabetes Care 1990; 13: 631-654.

7. Sawicki PT, Heinemann L, Starke A, Berger M: Hyperinsulinaemia is not linked with blood pressure elevation in patients with insulinoma. Diabetologia 1992; 35: 649-652.

8. Brands MW, Mizelle HL, Gaillard CA, Hildebrandt DA, Hall JE: The hemodynamic response to chronic hyperinsulinemia in conscious dogs. Am J Hypertens 1991; 4: 164-168.

9. Anderson EA, Hoffman RP, Balon TW, Sinkey CA, Mark AL: Hyperinsulinemia produces both sympathetic neural activation and vasodilation in normal humans. J Clin Invest 1991; 87: 2246-2252.

10. Anderson EA, Mark AL: The vasodilator action of insulin. Implications for the insulin hypothesis of hypertension. Hypertension 1993; 21: 136-141.

11. Kahn AM, Seidel CL, Allen JC, O'Neil RG, Shelat $H$, Song $T$ : Insulin reduces contraction and intracellular calcium concentration in vascular smooth muscle. Hypertension 1993; 22: 735-742.

12. Trovati M, Anfossi G, Cavalot F, Massucco P, Mularoni E, Emanuelli G: Insulin directly reduces platelet sensitivity to aggregating agents. Studies in vitro and in vivo. Diabetes 1988; 37: 780-786.

13. Hiramatsu $\mathrm{K}$, Nozaki $\mathrm{H}$, Arimori S: Reduction of platelet aggregation induced by euglycaemic insulin clamp. Diabetologia 1987; 30: 310-313.

14. DeFronzo RA, Tobin JD, Andres R: Glucose clamp technique: a method for quantifying insulin secretion and resistance. Am J Physiol 1979; 237: e214-e223.

15. Kageyama $\mathrm{S}$, Yamamoto $\mathrm{J}$, Ishibashi $\mathrm{K}$, et al: Comparison of effects of nicardipine and trichlormethiazide on insulin sensitivity in hypertensive patients. Am J Hypertens 1994; 7: 474-477.

16. Sherwin RS, Kramer KJ, Tobin JD, et al: A model of the kinetics of insulin in man. J Clin Invest 1974; 53: 1481-1492.

17. Clemens AH, Hough DL, D'Orazio PA: Development of the Biostator Glucose clamping algorithm. Clin Chem 1982; 28: 1899-1904.

18. Grynkiewicz G, Poenie M, Tsien RY: A new generation of $\mathrm{Ca}^{2+}$ indicators with greatly improved fluorescence properties. J Biol Chem 1985; 260: 34403450.

19. Kuriyama S, Nakamura $\mathrm{K}$, Horiguchi $\mathbf{M}$, Uchida $\mathrm{H}$, Sakai O: Decreased insulin-sensitive $\mathrm{Ca}^{2+}$ transport in cultured vascular smooth muscle cells from spontaneously hypertensive rats. Am J Hypertens 1992; 5: 892-895.

20. Touyz RM, Tolloczko B, Schiffrin EL: Insulin attenuates agonist-evoked calcium transients in vascular smooth muscle cells. Hypertension 1994; 23: i25i28.

21. Ouchi Y, Han SZ, Kim S, et al: Augmented contractile function and abnormal $\mathrm{Ca}^{2+}$ handling in the aorta of Zucker obese rats with insulin resistance. $D i$ abetes 1996; 45 (Suppl 3): S55-S58.

22. Kim YC, Zemel MB: Insulin increases vascular smooth muscle recovery from intracellular calcium loads. Hypertension 1993; 22: 74-77.

23. Saito F, Hori MT, Fittingoff $M$, Hino T, Tuck ML: Insulin attenuates agonist-mediated calcium mobilization in cultured rat vascular smooth muscle cells. $J$ Clin Invest 1993; 92: 1161-1167.

24. Ohno Y, Suzuki H, Yamanaka H, Nakamura M, Otsuka K, Saruta T: Impaired insulin sensitivity in young, lean normotensive offspring of essential hypertensives: possible role of disturbed calcium metabolism. J Hypertens 1993; 11: 421-426.

25. Zemel MB, Johnson BA, Ambrozy SA: Insulinstimulated vascular relaxation. Role of $\mathrm{Ca}^{2+}$. ATPase. Am J Hypertens 1992; 5: 637-641.

26. Pontremoli R, Zavaroni I, Mazza S, et al: Changes in blood pressure, plasma triglyceride and aldosterone concentration, and red cell cation concentration in patients with hyperinsulinemia. Am J Hypertens 1991; 4: 159-163.

27. Zemel MB, Sowers JR, Shehin S, Walsh MF, Levy $\mathrm{J}$ : Impaired calcium metabolism associated with hypertension in Zucker obese rats. Metabolism 1990; 39: 704-708.

28. Shimamoto $\mathrm{K}$, Hirata A, Fukuoka M, et al: Insulin sensitivity and the effects of insulin on renal sodium handling and pressor systems in essential hypertensive patients. Hypertension 1994; 23 (Suppl I): I-29-I33.

29. Pacheco CA, Lender D, Snell PG, et al: Relationship between insulin sensitivity, hyperinsulinemia, and insulin-mediated sympathetic activation in normotensive and hypertensive subjects. Am J Hypertens 1996; 9: $1172-1178$.

30. Gardner JP, Cho JH, Skurnick JH, et al: Blood pressure inversely correlates with thrombin-evoked calcium rise in platelets. Hypertension 1994; 23: 703709. 